\title{
Erythematous Papular Rash: A Dermatological Feature of COVID-19
}

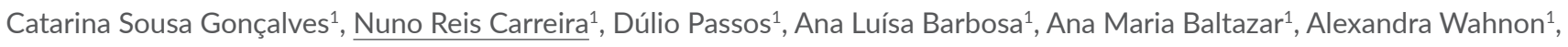 \\ Ana Mafalda Abrantes ${ }^{1}$, Pedro Miguel Garrido², Teresa Ferreira ${ }^{1}$, Marisa Teixeira Silva ${ }^{1}$, Lourdes Alvoeiro ${ }^{1}$ \\ ${ }^{1}$ Serviço de Medicina 2, Hospital de Santa Maria, Centro Hospitalar Universitário Lisboa Norte, Lisbon, Portugal \\ ${ }^{2}$ Serviço de Dermatologia, Hospital de Santa Maria, Centro Hospitalar Universitário Lisboa Norte, Lisbon, Portugal
}

\section{Doi: 10.12890/2020_001768 - European Journal of Case Reports in Internal Medicine - @ EFIM 2020}

Received: 01/06/2020

Accepted: 03/06/2020

Published: 10/06/2020

How to cite this article: Sousa Gonçalves C, Reis Carreira N, Passos D, Barbosa AL, Baltazar AM, Wahnon A, Abrantes AM, Garrido PM, Ferreira T, Teixeira Silva M, Alvoeiro L. Erythematous Papular Rash: A Dermatological Feature of COVID-19. EJCRIM 2020;7: doi:10.12890/2020_001768.

Conflicts of Interests: The Authors declare that there are no competing interests.

This article is licensed under a Commons Attribution Non-Commercial 4.0 License

\section{ABSTRACT}

COVID-19 is the clinical expression of the highly contagious severe acute respiratory syndrome coronavirus 2 (SARS-CoV-2) viral infection. Most patients have mild symptoms, but a significant proportion have severe or critical disease, which can include cardiac injury, sepsis, acute kidney failure and respiratory failure. It is also worth highlighting the increasing number of reported COVID-19 cases with dermatological disease/manifestations. The cutaneous clinical spectrum is wide and includes maculopapular, urticarial, varicelliform and petechial rashes, pseudo perniosis, livedo reticularis, and pityriasis rosea-like, violaceous and pustular lesions. Until the physiological mechanism is fully understood, it is important to describe these manifestations, which could help identify a typical pattern. This report describes a cutaneous manifestation in a COVID-19 patient.

\section{LEARNING POINTS}

- SARS-CoV-2 presents with multiple symptoms with the dermatological manifestations currently under-recognized.

- Clinicians should be aware of patients presenting only with cutaneous symptoms, which in some cases are the initial clinical feature of COVID-19.

\section{KEYWORDS}

SARS-CoV-2, cutaneous manifestations

\section{INTRODUCTION}

The SARS-CoV-2 virus appeared for the first time in December 2019 in Wuhan, China. It belongs to the coronavirus family, a large group of human and animal viruses that cause around $10-30 \%$ of mild upper respiratory tract infections ${ }^{[1]}$. The SARS-CoV- 2 virus can be transmitted animal-to-human and human-to-human and has a high contagion rate, even in asymptomatic individuals. Spread is via droplets projected by sneezing or coughing and then inhaled or absorbed by mucous membranes (mouth, nose and eyes). The clinical presentation of SARSCoV-2 infection is called COVID-19 and has a wide spectrum of clinical manifestations.

At the beginning of the COVID-19 pandemic, various symptoms were identified such as hyposmia or anosmia (in over $80 \%$ of patients) ${ }^{[2]}$, fever (80\%), dry cough (56\%), fatigue (22\%), myalgia (7\%) ${ }^{[3]}$, runny nose, sore throat, diarrhoea, bloody cough and chills. As with other viral infections, SARS-CoV-2 may also have cutaneous manifestations. 


\section{CASE DESCRIPTION}

A 57-year-old Caucasian man was admitted in the emergency room with a 4-day history of fever, cough, diarrhoea and malaise. His clinical history included arterial hypertension but was otherwise unremarkable. At presentation, he was febrile with a tympanic temperature of $38.9^{\circ} \mathrm{C}$ and hypoxic, with an arterial oxygen partial pressure of $61.3 \mathrm{mmHg}$. Laboratory investigation showed mild leucopenia $(4940 / \mu \mathrm{l})$, C-reactive protein of $9.25 \mathrm{mg} / \mathrm{dl}$, procalcitonin of $0.08 \mathrm{ng} / \mathrm{l}$, D-dimer of $0.08 \mathrm{ng} / \mathrm{l}$ and lactate dehydrogenase of $351 \mathrm{U} / \mathrm{l}$. Urinary antigens for Streptococcus pneumoniae and Legionella pneumophila were negative, blood cultures were negative, and there was no evidence of bacterial infection. Computed tomography of the thorax showed a typical COVID-19 pattern with bilateral pulmonary opacities, with predominant peripheral and basal distribution. The reverse transcription polymerase chain reaction test (RT-PCR test) for SARS-CoV-2 was positive and the patient was admitted to a COVID-19 ward. In the absence of complications, supportive therapy (including oxygen therapy) was initiated. On the 6th day of illness, the patient presented an urticarial rash (an erythematous papular rash with irregular contours) on the elbows (Fig. 1) and abdomen (Fig. 2). There were no newly initiated drugs, and the patient did not have atopy or a clinical history of allergy or other conditions that could explain the rash. In the absence of other possible syndromes and diseases, the skin rash was very likely due to SARS-CoV-2 infection.

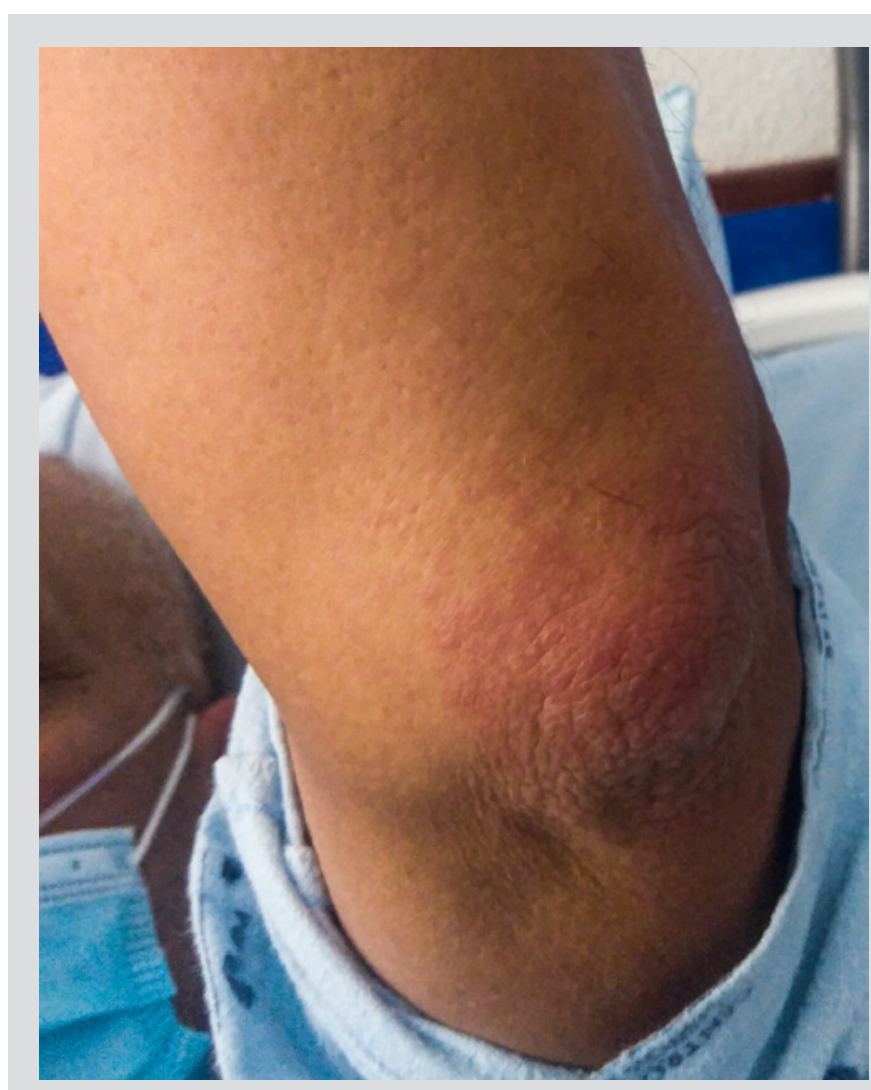

Figure 1. Erythematous papular rash on the elbow

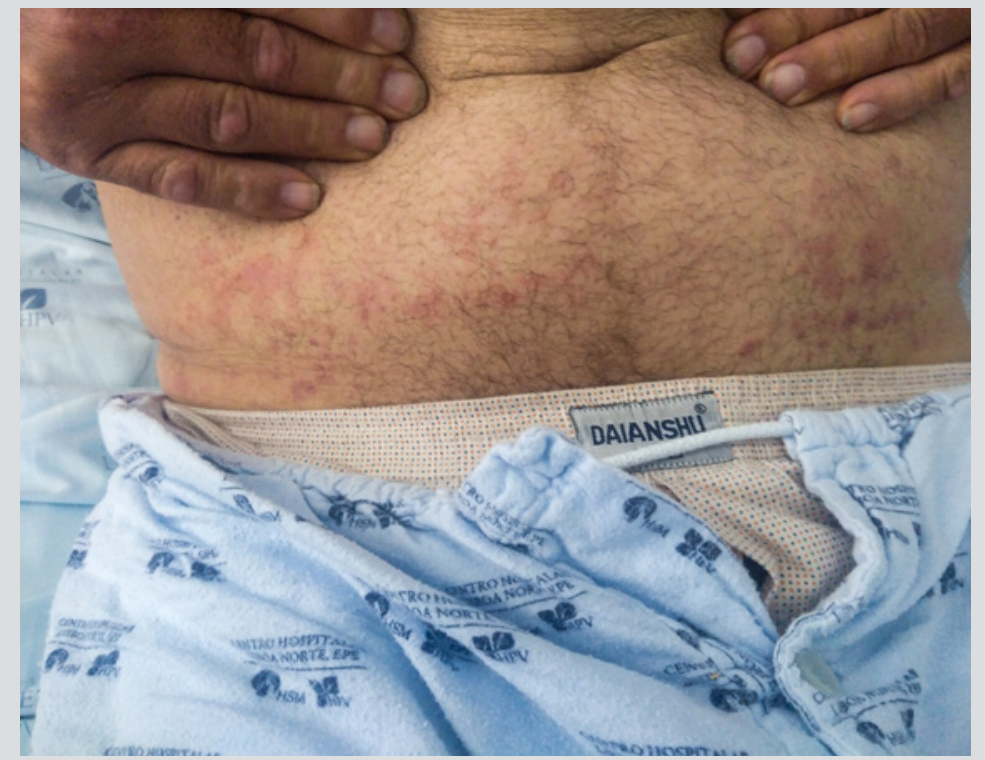

Figure 2. Erythematous papular rash on the abdomen

\section{DISCUSSION}

As the COVID-19 pandemic evolves, knowledge about the virus and its different dermatological manifestations is increasing ${ }^{[4]}$. The spectrum of clinical manifestations is very wide and includes skin disease. However, the presence of cutaneous manifestations as isolated symptoms associated with different aetiologies (infectious, vascular, inflammatory or traumatic) is making correlation difficult. The cutaneous manifestations include maculopapular, urticarial, varicelliform and petechial rashes, pseudo perniosis, livedo reticularis, pityriasis rosea-like and violaceous lesions, and vesicular and maculopapular pustular lesions (as in other viral infections).

The prevalence of the different rashes varies by geographical location; for instance, in a case series study carried out in Murcia, Spain, the most frequent manifestation was urticarial rash, while in Lombardy, Italy, erythematous rash was the most frequent cutaneous symptom ${ }^{[5]}$. 


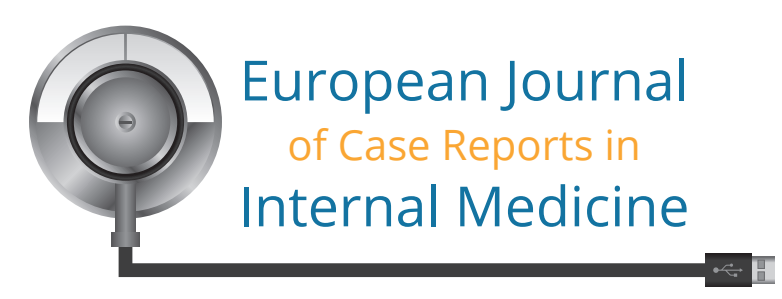

There are not yet enough studies to allow clinicians identify particular cutaneous patterns in COVID-19. Therefore, it is important to report such cases in order to increase knowledge about these symptoms, especially as they can be the only sign of infection and are easily confused with other viral or dermatological disease. We emphasize the importance of identifying the physiological mechanisms and chronological patterns, and of understanding if there is a symbiotic or synergistic relationship with other viral processes such as infectious erythema, herpes zoster and other skin diseases. We also highlight the critical importance of skin examination in COVID-19 patients.

\section{REFERENCES}

1. Paules $\mathrm{Cl}$, Marston HD, Fauci AS. Coronavirus infections-more than just the common cold. JAMA 2020;323(8):707.

2. Hornuss D, Lange B, Schröter N, Rieg S, Kern WV, Wagner D. Anosmia in COVID-19 patients. Clin Microbiol Infect 2020 May 21. doi: https://doi.org/10.1016/j.cmi.2020.05.017 [Epub ahead of print].

3. Wujtewicz M, Dylczyk-Sommer A, Aszkiełowicz A, Zdanowski S, Piwowarczyk S, Owczuk R. COVID-19 - what should anaethesiologists and intensivists know about it? Anaesthesiol Intensive Ther 2020;52(1):34-41.

4. Catalá Gonzalo A, Galván Casas C. COVID-19 y piel. Actas Dermo-Sifiliogr 2020 May 13. doi: 10.1016/j.ad.2020.04.007 [Epub ahead of print]

5. Pérez-Suárez B, Martínez-Menchón T, Cutillas-Marco E. Hallazgos cutáneos en la pandemia de COVID-19 en la Región de Murcia. Med Clin (Barc) 2020 May 8. doi: 10.1016/j. medcli.2020.05.001 [Epub ahead of print]. 